\title{
Pharmaco-morbidity linkage: a feasibility study comparing morbidity in two pharmacy based exposure cohorts
}

\author{
Ron M C Herings, Albert Bakker, Bruno H C Stricker, Gert Nap
}

\begin{abstract}
Study objectives-The aims were (1) to compare discharge diagnoses and concurrent medication in a pharmacy based cohort of users of $\mathrm{H}_{2}$ receptor antagonists to those in a population of users of other drugs in the same period, who did not use $\mathrm{H}_{2}$ receptor antagonists; (2) to compare these results to those of a similar study performed with the Tayside record linkage scheme.

Design and setting-The study was a retrospective cohort study. The morbidity data from the only hospital in one medium sized city (62 000 inhabitants) were linked to the dispensing data of all five community pharmacies on an individual basis (April 1, 1986-December 31, 1989). In the absence of a unique patient identification number, data from pharmacies and hospital were linked by the combination of date of birth, gender, and general practitioner code. For every user of $\mathrm{H}_{2}$ receptor antagonists two controls were obtained from all patients who had not used these drugs, and matched for age (within 5 years), gender, and general practitioner. All discharge diagnoses which followed this first prescription up to December 31, 1989, in a patient in the index cohort, and during the same period in his or her matched controls, were included in the study.
\end{abstract}

Main results-In the index cohort $(\mathbf{n}=2174) 341$ persons were admitted (526 admissions) as against 398 persons (527 admissions) in the control cohort $(n=4348)$. There was increased morbidity in the index cohort, especially concerning the gastrointestinal system (peptic ulcers and malignancies, abdominal pain, gastrointestinal haemorrhage), but also concerning the musculoskeletal, respiratory, and circulatory systems. The morbidity in the last three groups corresponded with drugs used concomitantly by patients in the index cohort, so it was probably not causally related to the intake of $\mathrm{H}_{2}$ receptor antagonists but was rather an indicator of higher levels of morbidity in the index cohort.

Conclusions-The figures were grossly comparable to those of the Tayside record linkage scheme. Probabilistic linking with the patient characteristics of gender, date of birth, and general practitioner code can facilitate the undertaking of postmarketing surveillance studies.
To conduct postmarketing surveillance, availability of data concerning drug exposure and morbidity is a prerequisite. Since the pioneering work on record linkage and drug monitoring by Skegg and Doll, ${ }^{1}$ several automated systems for medical record linkage have been developed during the last decade. The importance of such systems is obvious since, in contrast to voluntary reporting schemes, these facilitate the assessment of relative risks by application of various epidemiological research designs (eg, cohort, case-control). Record linkage systems may be fast, flexible, and relatively inexpensive. ${ }^{2}$ In view of the forthcoming concerted registration procedures in the European Community for new chemical entities, with the potential consequences of rapid penetration of a product into the European market, such systems may become very important for the surveillance and assessment of drug risks.

A key feature of these systems is the accuracy of linking data from different registries on an individual basis. ${ }^{3}$ Linkage can be performed by using a unique patient identification number (deterministic linkage) or with a combination of patient characteristics (probabilistic linking), available in the registries which are linked. ${ }^{4-6}$ Most current systems make use of a unique identification number. Unfortunately, in most countries a patient identification number is not available on a nationwide basis. Even if available (eg, in the United Kingdom), this number is not consistently used for all medical and pharmaceutical registrations. ${ }^{5}$ Secondly, public arousal as regards privacy and confidentiality may disable its use for record linkage. ${ }^{7}$

In The Netherlands a unique patient identification number is not available but we showed that it is possible to link exposure and morbidity data with the probabilistic method. ${ }^{89}$ In this retrospective cohort study we compared the discharge diagnoses in patients on $\mathrm{H}_{2}$ receptor antagonists with patients not using these drugs. Our results are compared to a similar study with the Tayside record linkage scheme, as published in this journal and elsewhere in $1984 .^{10} 11$ Data on concurrent drug use were not available in the Tayside study. Since this may be a proxy of comorbidity, we sought to get more insight into comedication in a cohort of users of $\mathrm{H}_{2}$ receptor antagonists. A second objective was to test the feasibility of performing a cohort study with probabilistic linkage.

\section{Methods}

EXPOSURE AND MORBIDITY DATA

The "pharmaco-morbidity linkage" (PHARMO) 
system comprises a database in which dispensing data from 30 pharmacies are collected on an ongoing basis. Five of these community based pharmacies provide for the medicines prescribed to the patients (except for inpatient prescriptions) in a medium sized and isolated city of 62000 inhabitants. Since the participating pharmacies make use of different software, all data are converted to one database format in which drugs are coded according to the WHO recommended anatomical-therapeutic-chemical (ATC) classification. ${ }^{12}$ For every patient discharged from the only hospital in this city the main medical condition and up to nine other conditions are coded according to the 9th revision of the International classification of diseases. ${ }^{13}$

\section{LINKAGE}

In this study the reasons for admission (main medical condition) to the hospital in a four year period 1986-1989 $(n=36000)$ were linked to the patient exposure data on the basis of the date of birth, gender, and general practitioner reference number (GP code) of every individual. In those cases in which the GP code was not present in the pharmacy files, the most frequently prescribing general practitioner was assumed to be the general practitioner of the patient. In a random sample of 1713 individuals the vaiidity of this linking index was assessed by reference to the original name and address registers in hospital and pharmacy. In this sample the combination date of birth, gender and GP code facilitated linkage with a sensitivity and specificity of $91 \%$ and $96 \%$ respectively. ${ }^{89}$

PATIENT AND CONTROL SELECTION

The index cohort consisted of all patients who had received one or more prescriptions of an $\mathrm{H}_{2}$ receptor antagonist between the start of the

Table I Hospital discharges among $\mathrm{H}_{2}$ receptor antagonist users and controls

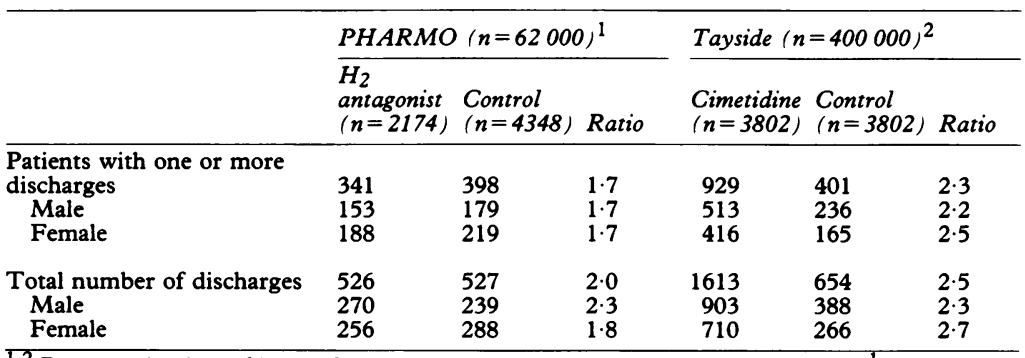

1,2 Betwween the date of issue of the first $\mathrm{H}_{2}$ receptor antagonist prescription and ${ }^{1} 31$ December 1990,231 December 1981 registration period per pharmacy and January 1 , 1990. The starting point of the observation period per patient was the date of the first recorded dispensing of an $\mathrm{H}_{2}$ receptor antagonist (cimetidine, ranitidine, and famotidine), whereas the endpoint was December 31 1989. Two controls were obtained for each index patient from the same pharmacy and matched for age (within five years), gender, and general practitioner. To ensure that they were eligible for health care in this period, only controls were enrolled who had received one or more prescriptions (but $n o \mathrm{H}_{2}$ receptors antagonists) in the observation period of the matched index patient.

\section{DATA ANALYSIS}

The index and control cohorts were linked to the disease registry and the reasons for and numbers of admissions which occurred in the study period of the index patients were compared to those of their matched controls. For the observation period of every index patient the indentical time interval of its matched controls was studied and the numbers of diagnoses in index and control groups were expressed as relative risks. Rate ratio estimations were made by dividing overall admission rates. The concomitant drug use in the study period in index and control cohorts was assessed per ATC group by counting every patient who had received one or more drugs classified within this ATC group, irrespective of the dose or duration of intake. Concomitant drug use was expressed as the "risk" of using a drug classified within a specified ATC group in the study period in the index cohort, relative to the "risk" of using a drug classified within the same ATC group in the control cohort . No adjustment was made for multiple comparisons of ATC groups. All rate ratios/relative risks are expressed as point estimates with $95 \%$ confidence intervals. ${ }^{14}$

\section{Results}

A total of 831109 prescriptions were dispensed between April 1, 1986, and January 1, 1990 in a mean observation period of 28.9 months. In this period 9785 prescriptions $(1.2 \%)$ of $\mathrm{H}_{2}$ receptor antagonists were dispensed to 2296 patients, $3 \cdot 7^{\circ}$ o of the city population, with a mean of 4.3 prescription per index patient. Excluded were 122 patients since their date of birth and/or GP code
Table II Number of discharges in major disease groupings among $\mathrm{H}_{2}$ receptor antagonist users and controls

\begin{tabular}{|c|c|c|c|c|c|c|c|}
\hline \multirow[b]{2}{*}{ Disease group } & \multirow[b]{2}{*}{$I C D-9-C M^{\mathrm{a}}$} & \multicolumn{3}{|c|}{ PHARMO $(n=62000)$} & \multicolumn{3}{|c|}{ Tayside $(n=400000)$} \\
\hline & & $\begin{array}{l}\mathrm{H}_{2} \\
\text { antagonist } \\
(n=2174)\end{array}$ & $\begin{array}{l}\text { Control } \\
(n=4348)\end{array}$ & $\begin{array}{l}\text { Relative } \\
\text { risk } \\
\left(95^{\circ}{ }_{0} C I\right)\end{array}$ & $\begin{array}{l}\text { Cimetidine } \\
(n=3802)\end{array}$ & $\begin{array}{l}\text { Control } \\
(n=3802)\end{array}$ & $\begin{array}{l}\text { Relative } \\
\text { risk } \\
\left(95^{\circ}{ }_{0} C I\right)\end{array}$ \\
\hline \multirow{9}{*}{$\begin{array}{l}\text { Digestive system } \\
\text { Signs, symptoms and ill } \\
\text { defined conditions } \\
\text { Musculoskeletal system } \\
\text { Neeplasms } \\
\text { Respiratory system } \\
\text { Circulatory system } \\
\text { Genitourinary system } \\
\text { Diseases of the skin } \\
\text { Nervous system and sense } \\
\text { organs }\end{array}$} & $(520-579)$ & 73 & 28 & $5.2(3.38-8.04)^{\star}$ & 515 & 52 & $9 \cdot 9(7 \cdot 47-13 \cdot 1)^{\star}$ \\
\hline & $(780-799)$ & 67 & 54 & $2.5(1.74-3.57)^{\star}$ & 195 & 62 & $3 \cdot 1(2.37-4 \cdot 17)^{\star}$ \\
\hline & $(710-739)$ & 46 & 62 & $1.5(1.00-2.23)^{\star}$ & 72 & 38 & $1.9(1.28-2.79)^{\star}$ \\
\hline & $(140-239)$ & 47 & 27 & $3.5(2.17-5.57)^{\star}$ & 163 & 87 & $1.9(1.45-2.41)^{\star}$ \\
\hline & $(460-519)$ & 31 & 35 & $1.8(1 \cdot 10-2 \cdot 86)^{\star}$ & 93 & 53 & $1.8(1.26-2.45)^{\star}$ \\
\hline & $(390-459)$ & 84 & 108 & $1.6(1 \cdot 18-2 \cdot 06)^{\star}$ & 199 & 116 & $1.7(1.37-2 \cdot 15)^{\star}$ \\
\hline & $(580-629)$ & 18 & 30 & $1.2(0.67-2 \cdot 15)$ & 89 & 58 & $1.5(1 \cdot 11-2 \cdot 13)^{\star}$ \\
\hline & $(680-709)$ & 1 & 7 & $0.3(0.04-2 \cdot 32)$ & 30 & 26 & $1.2(0.68-1.95)$ \\
\hline & $(320-389)$ & 37 & 51 & $1.5(0.95-2.21)$ & 42 & 39 & $1 \cdot 1(0 \cdot 70-1 \cdot 68)$ \\
\hline
\end{tabular}

$\mathrm{CI}=$ confidence interval

ath Revision of International classification of diseases

b Adapted from

* Significant difference in discharges use among $\mathrm{H}_{2}$ receptor antagonist users and controls 
had not been recorded. Because two controls were matched with each index patient the control cohort had twice as much person-year experience as the index cohort. The average person-year experience in both cohorts was 1.61 year. The mean age in both the index $(n=2174)$ and control $(n=4348)$ cohorts was 60 years. In both cohorts $53 \%$ of patients were female. The total number of prescriptions in the index group was $59668(27.5$ prescriptions/patient) as against 63173 (14.5 prescriptions/patient) in the control group.

\section{ADMISSIONS}

A total of 6635 patients who had used one or more prescriptions was admitted to the hospital, thus representing $10.7 \%$ of the city population $(n=62000)$. In the index cohort 341 out of 2174 patients $(15.7 \%)$ had been admitted once or several times (total number of admissions: 526 ) during the study period, whereas the 398 control patients $(9 \cdot 2 \%)$ accounted for a total of 527 admissions. The admission rate in the index cohort was $1 / 6.5$ person-years as against an admission rate in the control cohort of $1 / 13 \cdot 1$ person-years. The admission rate ratio in index versus control cohort was calculated at $2.0(95 \%$

Table III Number of discharges among $\mathrm{H}_{2}$ receptor antagonist users and controls

\begin{tabular}{|c|c|c|c|c|c|}
\hline \multirow[b]{2}{*}{ Disease group } & \multirow[b]{2}{*}{$I C D-9-C M^{\mathrm{a}}$} & \multicolumn{2}{|c|}{ PHARMO $(n=62000)$} & \multicolumn{2}{|c|}{ Tayside $(n=400000)$} \\
\hline & & $\begin{array}{l}\mathrm{H}_{2} \\
\text { antagonist } \\
(n=2174)\end{array}$ & $\begin{array}{l}\text { Control } \\
(n=4348)\end{array}$ & $\begin{array}{l}\text { Cimetidine } \\
(n=3802)\end{array}$ & $\begin{array}{l}\text { Control } \\
(n=3802)\end{array}$ \\
\hline \multirow{10}{*}{$\begin{array}{l}\text { All digestive system } \\
\text { Oesophagus, stomach and } \\
\text { duodenum } \\
\text { Peptic ulcers } \\
\text { Diseases of the oesophagus } \\
\text { Other diseases of the stomach } \\
\text { and duodenum } \\
\text { Gastrointestinal haemorrhage } \\
\text { Hiatus hernia } \\
\text { Gallbladder and biliary tract } \\
\text { Cancer of the oesophagus and } \\
\text { stomach }\end{array}$} & $(520-579)$ & 73 & 28 & 515 & 52 \\
\hline & & & & & \\
\hline & $\begin{array}{l}(530-537) \\
(531-533)\end{array}$ & $\begin{array}{r}16 \\
8\end{array}$ & $\begin{array}{l}1 \\
0\end{array}$ & $\begin{array}{l}331 \\
207\end{array}$ & $\begin{array}{l}9 \\
2\end{array}$ \\
\hline & (530) & 0 & 0 & 87 & 3 \\
\hline & & & & & \\
\hline & $(534-537)$ & 8 & 1 & 37 & 4 \\
\hline & $(578)$ & 5 & 0 & 27 & 1 \\
\hline & $(553 \cdot 3)$ & 8 & 0 & 15 & 2 \\
\hline & $(574)$ & 14 & 2 & 35 & 2 \\
\hline & $(150-151)$ & 9 & 2 & 40 & 1 \\
\hline
\end{tabular}

confidence interval: $1 \cdot 8-2 \cdot 2)$. Analysis by gender and by number of discharges gave similar results (table I).

Discharge diagnoses in index and control groups in this study are compared to those of the Tayside system in table II. Increased morbidity concerning diseases of the digestive system was present in the index cohorts in both systems but increased morbidity was also noted in other disease categories, such as neoplasms, and diseases of the musculoskeletal, circulatory and respiratory systems. No significantly increased morbidity was seen in our study for diseases of the skin, genitourinary, and central nervous systems. Table III represents a more detailed analysis of discharge diagnoses of the digestive system. Besides the expected increase in the numbers of index patients with peptic and duodenal disease, gastrointestinal haemorrhage, and abdominal pain, there was also a substantial increase in the discharge diagnoses concerning the gallbladder and biliary tract and hiatus hernia. The number of cancers of the oesophagus and stomach was relatively high.

\section{CONCURRENT MEDICATION}

The pharmacy files contain information on all drugs dispensed during the study period. A comparison of the concomitant drug use as distinguished in several ATC groups is presented in table IV. For every ATC group a relative risk was calculated for index patients and controls, and separately for those who had (inpatients) and had not (outpatients) been admitted. Drugs classified within most ATC groups were more frequently used in the index cohort than in the control cohort (table IV, column VI). This was shown most clearly in the outpatient groups (table IV, column IV). In the inpatient group (table IV, column II) the use of drugs for treating gastointestinal problems (ATC groups A03, A04, and A06) predominated but the use of vitamins A11,

Table IV Concurrent medication among $\mathrm{H}_{2}$ receptor antagonist users and controls for the most frequently used ATC drug groups

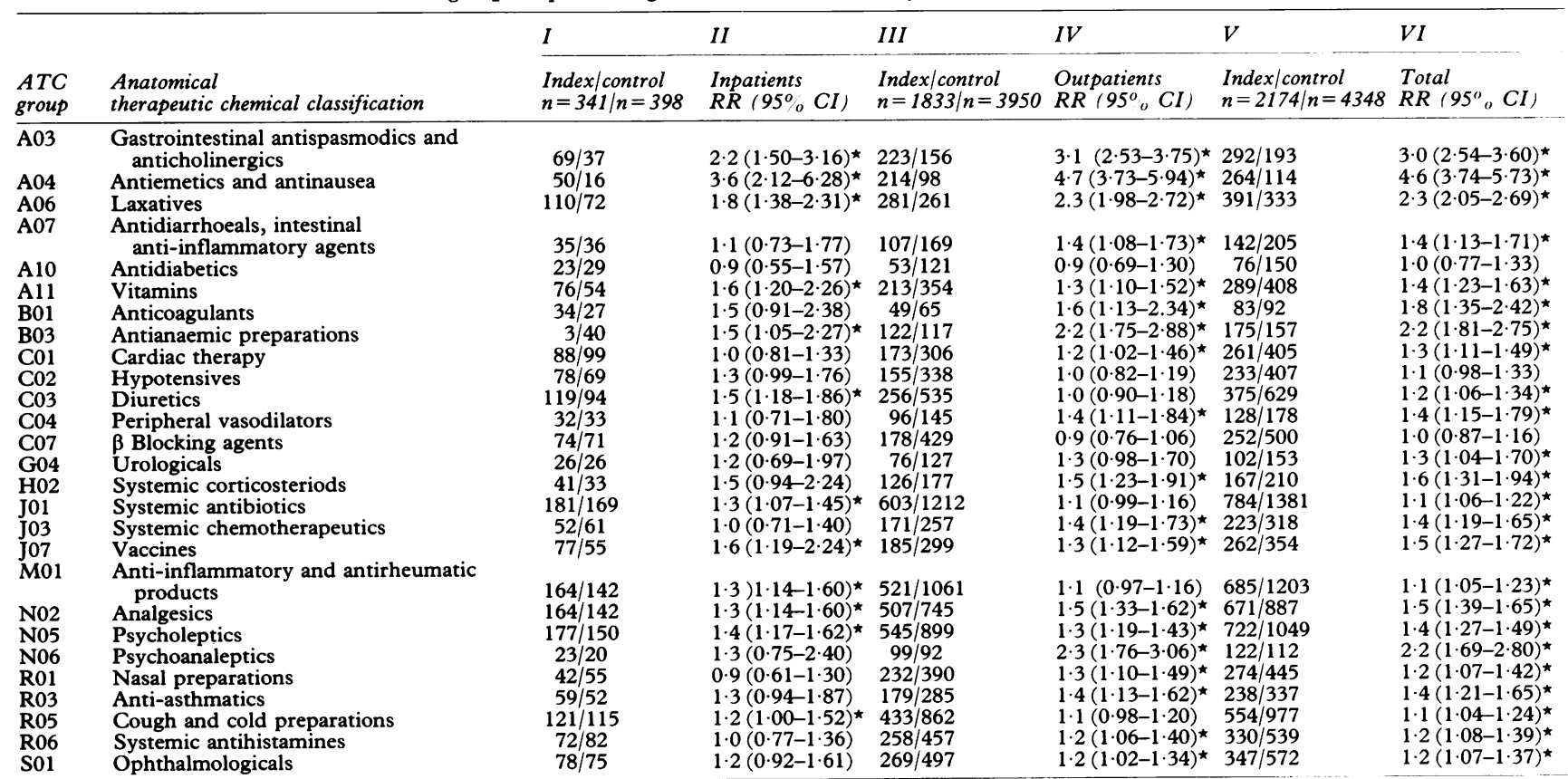

$\mathrm{CI}=$ confidence intervals
$\star$ Significant difference in drug use among $\mathrm{H}_{2}$ receptor antagonıst users and controls 
antianaemic preparations (B03), diuretics (C03), systemic antibiotics (J01), anti-inflammatory and antirheumatic products (M01), analgesics (N02), psycholeptics (N05), and cough and cold preparations (R05) was also increased compared to controls.

\section{Discussion}

In this feasibility study there was a significantly increased rate ratio of admissions in the cohort of patients treated with $\mathrm{H}_{2}$ receptor antagonists as compared to the control cohort. This increase was partly explained by an enhanced number of discharge diagnoses of gastrointestinal problems, but in addition the number of discharge diagnoses related to morbidity in several other bodily systems was also increased.

Three types of morbidity could be distinguished in the index cohort. Firstly, there was the morbidity or comorbidity due to peptic complications, which may be directly related to the reason for use of $\mathrm{H}_{2}$ receptor antagonists, eg, peptic ulcers, abdominal pain, or dyspepsia. The increase of diagnoses concerning the gallbladder and biliary tract, as seen in both the Tayside scheme and in our study, is possibly explained by those cases in which the initial symptoms were wrongly attributed to peptic ulcer disease. Similarly, some of the cases of gastrointestinal malignancy may be due to misjudgment of symptoms. Secondly, some discharge diagnoses may be related to adverse effects of $\mathrm{H}_{2}$ receptor antagonists. These may be difficult to detect since the incidence of adverse effects due to these drugs as a cause for hospital admission is probably low. Large record linkage systems and a well chosen research hypothesis are essential to identify and quantify these effects. Thirdly, there is the unexplained increase in admissions due to morbidity in other systems. The complex morbidity pattern in users of $\mathrm{H}_{2}$ receptor antagonists has also been noted in other studies. ${ }^{15}$ As drugs are prescribed to treat prevailing morbidity, concurrent drug use is an indicator for (co-)morbidity. It is obvious from table IV (column VI) that most ATC groups were used more frequently in the index than the control cohort. This is consistent with the higher overall number of prescriptions used in the index cohort. This strongly suggests that the prevalence of morbidity in the index cohort was higher than in the control cohort. Interestingly, in the hospital inpatient group (table IV, column II) the increase in disorders of the gastrointestinal, musculoskeletal, respiratory, and circulatory systems was compatible with the significantly increased use of gastrointestinal antispasmodics and anticholinergics (A03), antiemetics and antinauseants (A04), laxatives (A06), vitamins (A11), antianaemic preparations (B03), diuretics (C03), anti-inflammatory and antirheumatic products (M01), analgesics (N02), and cough and cold preparations (R05). It is unlikely that these effects reflect adverse effects to $\mathrm{H}_{2}$ receptor antagonists. More likely, these drugs are relatively frequently used in patients with other illnesses and not causally related to these diseases.

The design of this feasibility study was largely similar to that performed with the Tayside record linkage system, ${ }^{1011}$ but there were some differences. Firstly, because of the smaller population we made our study period longer. Secondly, at the moment of performing the Tayside study, cimetidine was the only agent marketed in the United Kingdom. Despite the fact that more $\mathrm{H}_{2}$ receptor antagonists were involved in our study, however, the results were remarkably similar. There was, however, in both index and control patients a much lower overall admission rate in this study than in the Tayside study. It is uncertain whether this is due to a variation in regional and/or national morbidity patterns, health care service, or both. Although the admission rate ratios in both studie, were comparable, the ratios in our study were consistently lower. Also the relative risk for diseases of the digestive system is of lower magnitude in our study. There are three possible explanations for this difference. Firstly, and most likely, our study was performed 10 years after the introduction of $\mathrm{H}_{2}$ receptor antagonists on the market in a phase when these agents are increasingly used for all kinds of dyspeptic complaints and abdominal pain. ${ }^{16}$ In the Tayside study cimetidine had been introduced fairly recently, and it is likely that at that time its use was more rigorously restricted to patients with demonstrated peptic ulcer disease. This is compatible with the much lower overall percentage of users of $\mathrm{H}_{2}$ receptor antagonists in the Tayside study. Obviously, as regards peptic ulcer related admissions, this would lead to a relative risk of higher magnitude. Secondly, in the Tayside study community based controls were enrolled. The use of community based controls would inflate the relative risk estimation if the control has died or moved to another area. In our study each control patient had had a prescription in the study period. This guaranteed that both index and control patients were eligible for medical services, and thus were alive and present in the area. Thirdly, one might argue that pharmacy based controls are generally more ill than community based controls, which would ultimately lead to more admissions. This is, however, not a likely explanation since over a three year period more than $90^{\circ}{ }_{0}$ of the population obtains one or more prescriptions (Herings R M C, unpublished data). This means that a randomly chosen pharmacy based control is probably representative of the total city population. Moreover, the much lower overall admission rate in the controls in our study than in those of the Tayside study is not consistent with higher morbidity.

The PHARMO system has some advantages. Although probabilistic linkage seems to be a disadvantage because of potential misclassification, this is not a great problem with a specificity of $96^{\circ}{ }_{0}$. Moreover, misclassification will be non-differential and does not influence the rate ratio of cohort studies because it will occur to the same extent in the index and control cohort. ${ }^{17}$ Although the use of a unique patient identification number makes linking more simple, the confidentiality of such numbers has raised public and political discussions. ${ }^{6}$ Moreover large indentification numbers are difficult to recall for the average individual, and hence such numbers 
are not consistently used. ${ }^{5}$ In the Tayside study no NHS number was found in $24 \%$ of prescriptions. ${ }^{10}$ In our study only the absence of gender and date of birth makes linking impossible, and so the percentage that could not be linked (approximately 7\%) was much smaller. Another advantage of our system is that all drug data are automated and that, in contrast to the Tayside scheme, no manual extraction and coding of prescriptions is needed. As the collection of drug data is an integral part of the administrative procedures in automated pharmacies in The Netherlands-unlike the Tayside scheme-we have data on all other drugs dispensed to the index and control patients in the same period. This facilitates a further assessment of the concurrent morbidity in these patients. In the Tayside study, for instance, the increase in disease categories concerning the respiratory system led to speculation as regards smoking habits. Although the increased use of respiratory drugs could be compatible with this hypothesis, it could also be explained by underlying respiratory diseases. Another advantage of the availability of dispensing data is the recognition of other drug risk factors, drug-drug interactions, and detection of potential confounding variables. ${ }^{18}$ At this moment our scheme is much smaller than the Tayside scheme, but it is currently expanded to a population of 250000 individuals.

In conclusion probabilistic linkage with dispensing data from pharmacies and morbidity data from hospitals facilitates the performance of cohort studies. Similarly, with diagnoses as a starting point, case-control studies are possible. On the condition that both consumption and morbidity data are validated, this scheme could be a useful resource for the performance of postmarketing surveillance studies.
1 Skegg DCG, Doll R. Record linkage for drug monitoring. 7 Epidemiol Community Health 1981; 35: 25-31.

2 Walker AM. Large linked data resources. $\mathcal{f}$ Clin Res Drug Dev 1989; 3: 171-5.

3 Stergachis AS. Record linkage studies for post marketing drug surveillance: data quality and validity considerations. In: Hartzema AG, Porta MS, Tilson HH, eds. Pharmacoepidemiology: an introduction. Cincinatti: Harvey Pharmacoepidemiology: an int

4 Arellano MG, Petersen GR, Petitti DB, Smith RE. The Californian automated mortality linkage system CAMLIS). Am f Public Health 1984; 74: 1324-30.

5 Gill LE, Baldwin JA. Methods and technology of record linkage: some practical considerations. In: Baldwin JA Acheson ED, Graham WJ, eds. Textbook of medical record linkage. Oxford: Oxford University Press, 1987.

6 Newcombe HB, Fair ME, Lalonde P. Discriminating powers or partitial agreements for linking personal records. Part I: The logical basis. Methods Inf Med 1989; 28: 86-91.

7 Boethius G, Wiman F. Recording of drug prescriptions in the county of Jämtland, Sweden. II. Drug exposure of pregnant women in relation to course and outcome of pregnancy. Eur $\mathcal{f}$ Clin Pharm 1977; 12: 37-43.

8 Herings RMC, Stricker BHCh, Romunde van L, Bakker A. Validation of record linkage based on characteristics of the patient: a pilot study in The Netherlands. In: Muller NF, Hekster YA, eds. Progress in clinical pharmacy: rational use of drugs. Noordwijk: Amsterdam Medical Press, 1989: of drugs.

9 Herings RMC, Stricker BHCh, Bakker A. Farmacomorbiditeitskoppeling (PHARMO): een pilot study naar de morbiditeitskoppeling (PHARMO): een pilot study naar de technische mogelijkheden in

10 Crombie IK, Brown SV, Hamley JG. Post marketing drug surveillance by record linkage in Tayside. $\mathcal{f}$ Epidemio Community Health 1984; 38: 226-31.

11 Crombie IK. Dundee record linkage study. In: Walker SR, Goldberg A, eds. Monitoring for adverse drug reactions. Lancaster: MTP Press Ltd, 1984: 81-9.

12 Guidelines for ATC classification. Nordic statistics on medicines 1981-1983. Part 3. Uppsala: Nordic Council on Medicines, 1985.

13 World Health Organization International classification of diseases. 9th revision, Clinical modification (ICD-9-CM) Geneva: WHO, 1978

14 Kahn HA, Sempos CT. Statistical methods in epidemiology. Oxford: Oxford University Press, 1989: 45-133.

15 Colin-Jones DG, Langman MJS, Lawson DH, Vessey MP. Review: post-marketing surveillance of the safety of Revievidin the problems of data interpretation. Aliment Pharmacol Ther 1987; 1: 167-77.

16 Brouwers JRBJ, Tygat GNJ. Recidief peptisch ulcer, beter voorkomen dan genezen? Pharm Weekbld 1985; 120:529-32. Rothman KJ. Modern epidemiology, 1st ed. Boston: Little Brown, 1986: 77-97.

18 Griffin JP. Final discussions. In: Walker SR, Goldberg A Griffin JP. Final discussions. In: Walker SR, Goldberg A, Press, 1983: 81-9. 